\title{
Development and Prospect of Friction Surfacing Technology
}

\author{
Mingfeng Li \\ School of Mechanical and Autumotive Engineering, Hefei University of Technology, Hefei, 230008, China
}

\begin{abstract}
Friction surfacing technology is a new type of solid-state processing technology. In friction surfacing, a viscoplasticized solid state region is generated resulting in a metallic bond between the plasticized material and the substrate. Friction surfacing has the unique advantage, but some shortcomings have restricted its further popularity and application over the years. This article summarizes the new progress of friction surfacing technology in equipment, welding technology and research of welding organizational performance, prospect of the future breakthroughs of the friction surfacing technology.
\end{abstract} process.

Keywords-friction surfacing; welding equipment; parameter;

\section{INTRODUCTION}

Friction Surfacing (FS) is an emerging surface engineering technology, derived from a conventional friction surfacing welding. In welding process, consumable rod is deposited on the substrate surface by the frictional heat as a driving force, and the deposition forms a metallurgical bond surfacing. Friction welding is a processing method of manufacturing technology based on the concepts of friction manufacturing technology, as with all the solid- state friction- based processing technologies, friction surfacing is more environmentally friendly and eliminate metallurgy defects in fusion welding, welding layer is better performance than the coating welded by fusion welding.

\section{FUNDAMENTALS}

Friction Surfacing is a solid- state process used for the production of metallic coatings of hot forged microstructures. A rotating consumable rod is fed against a substrate under an applied axial load rotary friction. Friction generates heat which generates a viscoplastic boundary layer at the rod tip. Subsequently, the consumable travels along the surface of the base metal, visco-plastic material is bonded to the surface of the base material, while pressure and heat conditions trigger an interdiffusion process, forming metallic bond between theplasticized material and the substrate. As the consumable rod material undergoes a thermomechanical process, a fine- grained microstructure is produced by dynamic recrystallization.

The speed difference between the viscoplastic material, which is rotating along with the rod, and the material effectively joined to the substrate, causes the deposit to detach from the consumable rod. This viscous shearing friction between the deposit and the consumable is the most significant heat source in the process [1].Due to the highly plasticized material of the lower end of consumable rod is pressed without restraint, resulting in the material flows out of consumable rod, so a flash is generated at the tip of consumable.

\section{DEVELOPMENT OF FRICTION WELDING TECHNOLOGY}

According to the basic principle of friction welding technology, new devices and new methods have been developed to overcome the low efficiency of the welding technology in recent years. Industrial applications of friction welding also contributed to the development of this technology. This paper provides overview throughout the development of welding equipment, promotion of welding process, as well as organizational performance of deposition and so on.

\section{DEVELOPMENT OF EQUIPMENT AND DEVICES}

Friction surfacing developed on the basic principle of friction welding. The welding equipment can be obtained by adjustment and equipment modification. In order to improve the efficiency of surfacing and adapt to different occasions, new welding equipment and devices have been developed to provide strong support for the promotion of friction surfacing.

In the process of friction surfacing, consumable rod is rigid materials. In order to avoid bucking, consumables is short out of the jig and fixture, which limits the ability to perform continuous welding without interrupting the welding process for reloading. As one kind of device [2] was designed for supporting and continuous feeding of the consumable rods, while avoiding buckling. This device improved continuity of friction surfacing, making it more suitable for the application of industrial promotion.

The use of CNC milling machine to clamp consumable rod and provide the feed rate of consumable rod [3] is widely applied. Ordinary CNC milling machine has high rigidity, and it is able to provide the load and torque for friction surfacing. The feed rate and trajectory of surfacing can be well controlled with this method, reducing the equipment cost and increasing the commercial viability of friction surfacing process.

A portable friction surfacing systems [4] for performing repairs of worn railway trails was developed. The system is mounted directly on the rail, providing the basis to apply the consumables axial load, and maintaining the stability of the system which can move along the longitudinal direction. This system also considers the angle adjustment in order to 
perform depositions along the different regions of the rail, reducing the costs of removing or interrupting railway circulation.

\section{A. Development of Welding Technology}

Effect of friction welding process parameters on the result is complex and far from linear, being strongly dependent on the base material and welding consumables. However, there are some typical trends and effects which can be found between process parameters and the result. Meanwhile, preheating, cooling and other processes also have a greater impact on the quality and efficiency of the surfacing.

The process parameters of friction surfacing affected on welding quality were widely discussed. The best combination of axial load, rotational speed, and speed in different applications is obtained through experiments. British scholar Vitanov [5] observed that for a given traverse and feed rates increase in rotational speed reduced the coating quality. However, for a given rotational speed there was a specific ratio between feed and traverse rates that had to be maintained for a good bond to exist. The main effect of the velocity ratio is the most significant factor on the process response. Introducing $\mathrm{Vz} / \mathrm{Vx}$ ratio reduces the variables influenced welding quality. Based on the relationship between parameters and welding results, predictive models can be developed to be applied in the design of new friction surfacing.

Portugal scholar Gandra et al. [6] found that when processing materials with a high melting temperature or thermal conductivity, pre-heating can be useful to soften and achieve the rate of plastic deformation. The difference of thermal properties between substrate and consumable rod can be attenuated by preheating and cooling. Application of cooling technology increases the advantage of friction surfacing. The use of rapid cooling has proven effective in tailoring the micro structural transformations following dynamic recrystallization, while controlling precipitation hardening. In order to get a faster cooling rate of deposition, American scholar Mishra et al. [7] deposited materials in underwater environments. Comparing to the deposition performance in air, underwater deposition was found to result in improved deposition efficiency, finer coating microstructures and higher hardness. However, underwater friction surfacing has limitations, it can't be applied in horizontal surfacing. A water spray cooling apparatus is developed, the water is ejected from the nozzle for cooling the surfacing deposition, which maintaining the advantages of underwater surfacing and avoiding the restriction.

In the current work, sound multi-layered deposits in various ferrous materials were realized using friction surfacing in both single- and multi-track approaches. Samples with fully enclosed internal cavities and those consisting of different materials in different layers were also successfully produced [8]. The deposits showed fine-grain wrought microstructures with excellent bonding between individual layers and tracks. Continuous friction surfacing has been adapted to the manufacturing of three-dimensional parts. Current research indicates that an emerging solid-state surface coating process can be developed based on friction surfacing. Three-dimensional metallic parts can be surfaced by multi-track friction surfacing, each size of deposition is slightly larger than the actual part, and then Semi-finished product is machined by $\mathrm{CNC}$ machine tools to from precision profiling of parts sliced, ultimately desired part is obtained.

In order to deposit consumable rod which has a highly superior mechanical strength than the substrate, a starter and finishing plate were introduced in friction surfacing process [9]. When consumable rod has a highly superior mechanical strength than the substrate, a starter plate is need to be set. Starter plates have a higher hardness than the substrate and are used just to initiate the plastic deformation. The consumable rod travels onto these substrate and perform main deposition. A finishing plate needs to be set for rod extraction. Starter and finishing plates expand the study scope of friction surfacing, and new material combinations can be studied.

\section{B. Research of deposition Properties}

Cr-Mo steel and austenitic stainless steel are widely applied in thermal and nuclear power plants. However, dissimilar metal joints welded by fusion welding can't meet the design life index. A novel weld transition joint by friction surfacing method is developed [10]. By between Cr-Mo steel and austenitic stainless steel cladding layer to make a series of nickel alloy welding material connecting the two metals. Weld transition joint between $\mathrm{Cr}-\mathrm{Mo}$ steel and austenitic stainless steel was developed by depositing series of Ni-alloy coatings between them. Because of the special advantages of friction surfacing, grain refinement and increase in hardness were observed. These multi-layered coatings with gradual rather than abrupt change in coefficient of thermal expansion between $\mathrm{Cr}-\mathrm{Mo}$ and austenitic stainless steels are expected to improve the service life of dissimilar metal welds.

Friction surfacing has been successfully used to apply self-mating layers onto cold work tool steels [11], such as deep-drawing dies in the automotive industry. Such dies are subject to wear during operation and the repair of the dies by arc-welding includes many process steps besides the final hard surfacing. By the use of friction surfacing, hard tool steel coatings can be generated in one process step before the final machining operation. A martensitic microstructure and high hardness up to $900 \mathrm{HV} 10$ can be reached within the coatings. The deposition of repair mold performs as well as the original die material, showing tribochemical reactions and very small wear volumes.

CrNi-alloys with high Cr-content generally are quite brittle and, therefore, only available as castings and regarded as neither weld able nor deformable. Defect free deposition of Cr60Ni40 with a thickness of about $250 \mu \mathrm{m}$ is achieved by friction surfacing [12]. The deposition shows a better wear behavior than the cast material under cavitation, which performances less deformation and small disruption, and the wear rate of the sample is lower than casting samples. Friction surfacing improves the wear resistance of 
chrome-nickel alloy deposition, and extends the range of applications of high-temperature corrosion resistant alloys.

\section{V.PROSPECTS OF FRICTION SURFACING}

Friction surfacing has developed for surfacing fine grained deposition, which exhibit superior wear and corrosion properties. Friction surfacing is an efficient surface engineering technology and has broad prospects. To make friction surfacing more competitive meeting the needs of different occasions, the following aspects need to work:

With the development of friction surfacing technology, special equipment has been difficult to adapt to the needs of other industries. The compatibility of welding equipment should be optimized according to different sizes and different properties of materials, improving welding parameters and establishing a standard process parameters database. The development of special friction welding equipment should be accelerated to improve the level of automation and production efficiency.

Advanced friction surfacing technology includes welding technology, monitoring technology and testing technology. The development of the basic theory of this technology is very important. During the study of the basic theory, a physical model can be established by computer, which is helpful for the study of friction surfacing process.

Friction surfacing has its own unique advantages and disadvantages. For better development, it should draw on the development and research ideas from other technologies. Friction surfacing has to integrate advanced science and current engineering technology, so that this technology can be applied to new fields.

\section{REFERENCES}

[1] Pedro Vilaca, Friction surfacing.Surface modification by solid state processing, 2014, 25-72.

[2] Hanlon T., Fritz J. B.\&Bernath J. J., Apparatus and method for friction surfacing using a consumable pin tool: US, 8056793. B2.2010-03-02.

[3] Vitanov V. I., Javaid N. \&Stephenson D. J., Application of response surface methodology for The optimization of micro friction surfacing process. Surface and coatings technology, 2012, 204, 3501-3508.

[4] Doughty R. W., Shaw D J. \& Gibson D. E., Friction stir surfacing process and device for treating : France, WO2009030960A1.2009-03-12.

[5] Vitanov V. I., Javaid N. \& Stephenson D. J., Application of response surface methodology for the optimisation of micro friction surfacing process. Surface and Coatings Technology, 2012,204(21-22), 3501-3508.

[6] Gandra J., Krohnb H. \& Mirandac R. M., Friction surfacing-A review. Journal of Materials Processing Technology, 2014, 214 (5) ,1062-1093.

[7] Mishra R. S. \&Ma Z. Y., Friction stir welding and processing. Materials Science and Engineering, 2005, 50(1-2), 1-78.

[8] Dilip J. J. S., Babu S. \& VaradhaRajan S., Use of Friction Surfacing for Additive Manufacturing. Materials and Manufacturing Processes, 2013, 28(2), 189-194.

[9] Rao K. P., Sankar A. \& Rafi H. K., Friction surfacing on nonferrous substrates: a feasibility study. International Journal of Advanced Manufacturing Technology, 2012, 65, 5-8.

[10] JavedAkram, Ramesh Puli\& Prasad RaoKalvala,A novel weld transition joint by friction surfacing. Manufacturing Letters, 2014, 2(4), Pages 104- 107.

[11] Hanke S., Beyer M. \& Fischer A., Friction surfacing of a cold work tool steel-Microstructure and sliding wear behavior. Wear, 2013, 308(1-2), 180-185.

[12] Hanke S., Beyer M. \& Fischer A., Cavitation erosion of Cr60Ni40 coatings generated by friction surfacing.Wear, 2013, 301(1-2), 415-423. 